\title{
Technical and Economic Assessment for the Promotion of Non- Carbonized Pellets in MSME Sector in Nepal
}

\author{
Suyesh Prajapati ${ }^{1, *}$, Aadit Malla ${ }^{1}$, Narayan Prasad Adhikari ${ }^{2, * *}$, Shubha Laxmi Shrestha ${ }^{2}$ \\ ${ }^{I}$ MinErgy Pvt. Ltd., Nakkhu, Lalitpur Nepal \\ ${ }^{2}$ Alternative Energy Promotion Center, Ministry of Energy, Water Resources and Irrigation, Government of Nepal \\ Khumaltar, Lalitpur, Nepal \\ Corresponding Email: suyesh.prajapati@minergynepal.com; \\ narayan.adhikari@aepc.gov.np
}

\begin{abstract}
:
Pellets are densified biomass fuel compatible for household as well as industrial use. Pellets can be potentially used as an alternative fuel source in many medium, small and micro enterprises (MSME) such as dairy, dyeing, laundry, khoa making, pickle making, yogurt making, soap making enterprises etc. in Nepal. Despite of the presence of large number of such industries and abundant biomass resources, production and application of pellets as a fuel source is almost non-existent in Nepal. Hence, to assess the benefits of using pellets as alternative fuel, an applied research of pellets application was carried out in a dyeing industry. Energy, environment and economic performances of the dyeing industry was compared between the baseline scenario of utilizing sawdust and wood chips mixture in loose form with that of non-carbonized pellets application as an alternative fuel. Results showed decrease in specific energy consumption by $6 \%$ on utilizing non-carbonized pellets compared to baseline. In terms of the environmental performance, emission of $\mathrm{CO}$ decreased from $100 \mathrm{Mg} / \mathrm{L}$ to $10 \mathrm{Mg} / \mathrm{L}$ and $\mathrm{CO}_{2}$ emission decreased from $7.5 \%$ to $4 \%$. Similarly, suspended particulate matter (SPM) emission decreased from $37.4 \mathrm{mg} / \mathrm{Nm}^{3}$ to $14.8 \mathrm{mg} / \mathrm{Nm}^{3}$ but the negligible increment of $\mathrm{NO}_{2}$ emission was observed. However, emission of $\mathrm{SO}_{2}$ increased significantly from $3.3 \mu \mathrm{gm} / \mathrm{m}^{3}$ to $33.7 \mu \mathrm{gm} / \mathrm{m}^{3}$. High Sulphur content was found in the pellet which could be from the lubrication used in the pellet machine, but this could not be confirmed. The economic analysis revealed that the energy cost was almost twice with pellet application which was mainly because of the higher cost of imported pellets. If the production could be initiated in Nepal, utilizing the abundantly available local biomass resources, the cost could be considerably lowered thus making use of such fuel economically feasible.
\end{abstract}

Keywords: MSMEs, Pellets, Specific Energy Consumption, Environmental Emissions, Economic Performances

\section{Introduction}

In a developing country like Nepal, MSMEs play a crucial role for the improvement of the national economy. Hence bringing about technological modifications to help these industries meet the present day performance standards is crucial. Many MSMEs in Nepal rely on traditional biomass energy sources such as sawdust, rice husk, maize stalk etc. The low energy density of the loose biomass results in higher energy consumption, high production cost and negative impacts on the system efficiency and environment. In addition, due to scarcity and disrupted supply of these traditional fuel sources, along with the poor performance, Nepali MSMEs have been searching for better performing energy source with reliable supply.

Use of densified biomass fuel, obtained from the abundantly available local resources such as agro residues, forest waste and other industrial wastes, could be one of the most suitable options for combustion based
MSMEs. Pelletizing is a densification process of loose biomass which makes fuel sources more compatible for industrial use. However, due to the lack of sustainable market in present context, the production of pellets has been minimal in the country. Hence the research was executed with an aim to assess the potential to promote pelletized biomass in the MSME sector in Nepal.

\section{Literature}

The term "biomass" refers to biological material from living or recently living organisms. The material may be in the form of forest residues, wood, crops with byproducts, municipal solid waste, animal wastes, wastes from different biomass- based industries, aquatic, and algae [1]. Biomass contains energy absorbed and stored from the sun during photosynthesis process and can be used in its original form as fuel, or be refined to different kinds of solid, gaseous or liquid biofuels. Industrial use of biomass is a common practice. When burnt, the chemical 
energy contained in it is released in the form of heat. The extraction of energy from such sources can be done either by direct burning, conversion to liquid bio fuels or biogas that can burned as fuels [2]. Biomass is used to meet a variety of energy needs, including electricity generation, space heating, and vehicle fuel as well as providing process heat for industrial facilities [3]. In least developed countries traditional biomass is often considered the dominant domestic fuel, especially in more rural areas without access to electricity or other energy sources. Researches show that about $90 \%$ of the total energy consumption in Nepal is obtained from biomass [4]. The abundantly found biomass in Nepal include fuel wood, rice husk, rice straw, maize stalk, wheat straw, sawdust, pine needles, bagasse etc. [5]. With sufficient economic and technical support, bioenergy could hold opportunities for sustainable development of any nation [6]. However the use of biomass in its loose form is inefficient, results in pollution and creates handling difficulties [7]. The use of densified biomass has gained popularity worldwide, as it improves the bulk density, energy density and reduces moisture content of the biomass [8]. Some possible densified biomass products are: bales, pellets, cubes, briquettes and pucks. The continuous combustion time of biomass pellets is 8 to 10 folds higher than that of loose biomass and hence making this highly suitable source of fuel in industrial boilers [9]. Use of pellets as fuel source is on the rise globally. Records show European Union Nations imported about 5 million tons of wood pellets from non-EU nations in 2014. [6]. Biomass pellets are generally produced without additives and only from the natural resources originating from biomass residue which is a part of the natural carbon cycle, thus making it net carbon neutral with no increased greenhouse gas emissions upon its generation. Also biomass pellets burn clean and are highly preferable to coal due to no negative impact on health and air quality [10]. With the availability of agro waste in large quantities in the country, the pellet production potential in Nepal is estimated at 11.21 metric ton with the generation of 83.5 Peta joule energy [11]

Industrial sector in Nepal consumes 29.7 million GJ of energy accounting almost $8 \%$ of the total energy consumption in the country [12]. About $90 \%$ of industrial energy is consumed by manufacturing industries [12]. Most Nepalese industries make inefficient use of fuel hence there is huge potential to improve energy consumption in those industries [13]. Fuel wood, electricity, diesel and coal are the main industrial fuels [12]. Due to the disrupted supply of traditional and imported fuel along with the elevated prices, many MSMEs in Nepal are looking for alternative sources which could be more efficient, environment friendly and cost effective. Considering the combustion technologies in use, fuel size and heating value, biomass pellets appear to be the most suitable alternative fuel for many MSMEs in Nepal. Taking into consideration the availability of large amount of biomass in Nepal [5], switching towards densified biomass fuel sources for these sectors could be ideal. Amongst the 8 different types of industries categorized by the Department of Cottage and Small Industries (DoCSI), the industries utilizing combustion technologies with loose biomass fuel sources, under the manufacturing category would be ideal for the pellet substitution.

Pellet production is initiated with the collection, drying and storage of the raw biomass such as sawdust, rice husk, agriculture residues etc. Drying of the biomass is important as processing in wet form requires more energy. The dried biomass is screened for removal of impurities and is passed through a hammer mill to achieve uniform size. The pulverized biomass is then passed through the pelletizer, where it is pre-heated to $120^{\circ} \mathrm{C}$ which makes the lignin in the raw biomass more plastic and adhesive. The biomass is then extruded through the pellet machine giving it a required shape and size. The sawdust exiting the pellet machine are cut into required lengths. The pellet leaving the matrix cool down immediately with the moisture content dropping to $6 \%$ and stabilizing at $8-10 \%$. After cooling the pellets are packed in bags of sizes as per market demand [15].

\section{Methodology}

As a first step, secondary data on the number and types of MSMEs operating within Kathmandu valley were collected to identify MSMEs suitable for pellet substitution. Since many such MSMEs in Nepal are operating informally without registration [14], determining the exact number of such enterprises was difficult. For pellet application, numerous MSMEs based on biomass combustion technologies were identified. Among several such MSMEs, dairy, dyeing and food industries were identified as the highly suitable ones as these MSMEs were found consuming much lower energy with need of continuous heat supply. However, both dairy and food industries had to be rejected due to the requirement of high steam flow rates for operation in the former and LPG use being common in the latter. Generating high steam flow rates from pellet is technically challenging and replacing LPG by pellets would require major technological modification. Also hygiene maintenance was important for food industries, which 
could be better achieved by LPG rather than pellet burning. Dyeing industries make use of boilers and require lower steam flow rates, thus making it ideal for pellet application. Furthermore the boiler size along with the requirement of steam flow rate and operating procedures of these industries were ideal for pellet application without the need for any major modification and alterations to the systems in place required for application. In addition, the dyeing industry's owners showed great interest and willingness towards fuel substitution. Thus, upon assessing different alternatives, dyeing industry was selected for pellet application.

Dyeing industries are common all around the country operating in different scales with varying production capacities. 20 large scale dyeing industries were operating in the vicinity of Kathmandu valley. Over the years, to accommodate with the growing market and mandated improved environment performance standards, the dyeing industries have significantly upgraded their operational technologies. The basic working principal of a dyeing industry includes the coloring of the yarn by heating colored water and circulating it over the yarn. The chamber or the vessel loaded with the yarn is filled with cold water. Heat is supplied to the cold water increasing it to almost boiling temperature. Required color is then added into it and stirred. The heated movement of the colored water results in the desired coloring of the yarn. Traditional and modern are two dying methods in use in industries. The traditional method, pot dyeing, utilizes locally made pots of copper or aluminum, with heat supplied via firewood burning or LPG, whereas the modern method utilizes specially designed dyeing machines with heat supplied from steam generated in boilers. The modern dyeing industries use various biomass in loose form to generate the required quantity of heat energy for boilers whose capacity ranges from 600 800 kilogram. The furnace used for supplying heat to the boilers vary depending on the properties of the biomass used. Fluidized bed furnace are common in most industries due to the low density of the loose biomass. However use of non-carbonized pellet in fluidized bed furnace would not be possible due to the increased density of the fuel source. Hence, sloping grate furnace was identified as the most suitable for pellet combustion. Thus, amongst the numerous dyeing industries, Dantakali Dyeing industry located at Mulpani, Kathmandu was selected for application mainly because of presence of a sloping grate furnace and willingness of the entrepreneur to test new fuel in his industry.

\subsection{Operation of Dantakali dyeing industry}

Dantakali dyeing industry produces about 600-800 kilogram of dyed wool operating 8 hours a day. The industry uses mixture of sawdust and woodchips as fuel source. The industry makes use of a boiler for the generation of steam which is utilized for heating the water in the dyeing machines. The steam generated from the boiler is provided to the individual machines which are loaded with the threads that require coloring. These machines are filled with cold water to the brim along with the thread. The steam generated from the boiler heats the cold water in the machines up to $70-80^{\circ} \mathrm{C}$. The required color is poured from the top of the machine. The water is then circulated within the machine with the help of motors. The warming of water along with the movement and color results in the absorption of colors by the thread and hence resulting in dyed threads. Depending on the size of the machine, the dyeing may take 2-4 hours.

The research was carried out in two phases; i) Baseline study and ii) Demonstration phase. In the baseline study, the energy, environment and economic performances of the industry was assessed in the business as usual condition, i.e. with sawdust and woodchips application. In the demonstration phase, the same parameters were assessed maintaining the same operating condition i.e. temperatures and pressure conditions but using noncarbonized pellets as a fuel source. Impacts of pellets application was determined by comparing the results of the baseline study and the demonstration phase.

The calorific value $(\mathrm{CV})$ and proximate properties of sawdust/woodchips and non-carbonized pellets were determined from the accredited laboratory at Central Department of Environmental Science (CDES), Tribhuvan University. The energy performance was assessed by measuring the Specific Energy Consumption (SEC) i.e. MJ of energy consumed per $\mathrm{kg}$ of product output. Emissions of Suspended Particulate Matter (SPM), Carbon Monoxide (CO), Carbon Dioxide $\left(\mathrm{CO}_{2}\right)$, Sulphur Dioxides $\left(\mathrm{SO}_{2}\right)$ and Nitrogen Dioxide $\left(\mathrm{NO}_{2}\right)$ were determined through stack measurement and laboratory analysis. The emission test was performed using Vayubodhan Stack Sampler (VSS1) instrument following the methodology as per IS 11255 (Part-1). The results from the tests, conducted over a period of one hour, during both the study phases were compared and analyzed. By comparing the expenses on fuel per $\mathrm{kg}$ product in the baseline and the demonstration phases, the economic performance was measured.

\section{Methodology}




\subsection{CV and Proximate Analysis of fuels}

Before initiating the field based testing, the CV and other properties of both fuel- sawdust/woodchips and pellets were determined through laboratory analysis. The sawdust pellets used during demonstration were imported from India. The result of the analysis is presented below:

Table 1: Tested Properties of fuel (Adapted from [15])

\begin{tabular}{|l|l|l|l|}
\hline $\begin{array}{l}\text { S. } \\
\text { No. }\end{array}$ & Sample No. & $\begin{array}{l}\text { Sulphur content } \\
\text { (wt. \%) }\end{array}$ & $\begin{array}{l}\text { Calorific Value } \\
\text { (MJ/kg) }\end{array}$ \\
\hline 1. & Sawdust mixture & $0.05 *$ & 12.39 \\
\hline 2. & Pellet Sample & 0.1 & 13.71 \\
\hline
\end{tabular}

Higher Sulphur content in pellets could be due to lubrication oils are used in the pelletizing machines during manufacturing. But the manufacturer was reluctant to share any information on the manufacturing process for pelletizing, hence the exact reason couldn't be determined.

\subsection{Fuel mix during baseline and demonstration phase}

\subsubsection{Baseline}

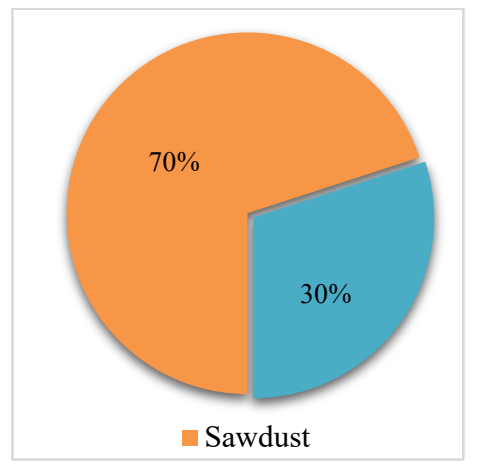

Figure 1: Baseline Fuel Mix

The industry utilizes sawdust mixture as its fuel source for day to day operation. The sawdust mixture constitutes of $70 \%$ sawdust and $30 \%$ woodchips by volume. The sawdust mixture tested for calorific value in the laboratory showed an average value of about $12.39 \mathrm{MJ} / \mathrm{kg}$. Over the two days baseline study period, the daily consumption of sawdust mixture for boiler heating was calculated. It was observed that the daily consumption of sawdust mixture primarily dependent on the quantity of production planned for a particular day, as with increased production quantity the steam requirement is bound to increase, which directly impacts the heat required by the boilers to meet the steam rates. Even though no specific procedure is followed for furnace feeding, the worker is required to maintain a pressure of $50 \mathrm{lb} / \mathrm{in}^{2}\left(1.38 \times 10^{6} \mathrm{~kg} / \mathrm{m}^{3}\right)$ in the boiler which is ideal for operation. On average, feeding is done every 20-30 minutes with each feed of about $70-80 \mathrm{~kg}$ of sawdust mixture. Also in-between fuel feeding, the sawdust mixture is used to cover the furnace feeding holes, to prevent suction of cold air which could lead to inefficient combustion in the furnace. This resulted in some additional fuel entering the furnace which could not be accounted for.

\subsubsection{Demonstration}

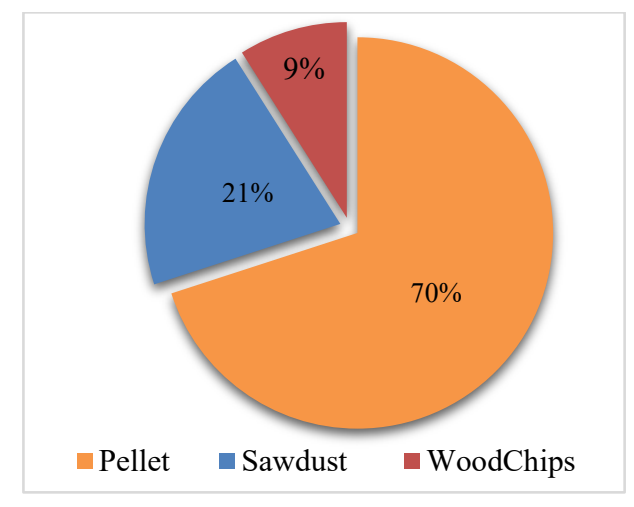

Figure 2: Demonstration Fuel Mix

Even though $100 \%$ sawdust mixture substitution by noncarbonized pellet was expected initially, this could not be achieved due to the slow ignition property of pellets which would interrupt or delay the operation of the dyeing process. Hence, sawdust mixture had to be used for initial firing to expedite the firing process and in-between feeding to cover the feeding holes. The initial ignition was done using sawdust mixture. The pellet feeding was done only after the furnace had reached the temperature ideal for pellet combustion. Hence, considering the sawdust used for initial ignition and for covering the feeding holes, only $70 \%$ fuel substitution could be achieved. The fuel mix achieved during demonstration is shown in the graph below. Regarding the pellet feeding mechanism, feeding pellets similar to the baseline resulted in the generation of black smoke from the chimney and incomplete combustion of pellets. Hence to overcome this, the feeding mechanism was modified with continuous feeding in small quantities. This significantly reduced the emission of black smoke and improved pellet combustion.

\subsection{Result and Analysis}

\subsubsection{Energy Performance}

The result showed that the consumption of fuel per kilogram of product output decreased from $1.04 \mathrm{~kg}$ (baseline) to $0.93 \mathrm{~kg}$ (demonstration). In terms of energy 
value, the specific energy consumption reduced from 13.28 MJ to $12.43 \mathrm{MJ}$ per kilogram of the product output from baseline to demonstration phase respectively. The reduction of specific energy consumption was about $6.5 \%$. This shows that pellet application results into improve combustion efficiency compared to loose biomass application. This finding accords with previous studies which claims that conversion efficiency of burning loose biomass can be as low as $40 \%$ [16].

\subsubsection{Environment Performance}

The environment performance showed mixed results. Emission of SPM, the major environmental concern for dyeing industries, decreased by $60 \%$ with pellet application. Emission of SPM decreased from 37.4 $\mathrm{mg} / \mathrm{Nm}^{3}$ to $14.8 \mathrm{mg} / \mathrm{Nm}^{3}$ from baseline to demonstration phase. Similarly, emission of CO decreased from 100 $\mathrm{Mg} / \mathrm{L}$ to $10 \mathrm{Mg} / \mathrm{L}$ and $\mathrm{CO}_{2}$ emission decreased from $7.5 \%$ to $4 \%$. This shows improve combustion efficiency with pellets than mixture of sawdust and woodchips.

However, emission of $\mathrm{SO}_{2}$ emission increased significantly from $3.6 \mu \mathrm{g} / \mathrm{m}^{3}$ to $33.7 \mu \mathrm{g} / \mathrm{m}^{3}$ with pellet application. The higher emission of $\mathrm{SO}_{2}$ is mainly due to higher sulphur content in the pellet compared to loose biomass. The cause for higher sulphur content in pellet couldn't be determined but its presence can be controlled selecting the right raw material and by improving the manufacturing process. Similarly, $\mathrm{NO}_{2}$ emission showed slight but negligible increment. $\mathrm{NO}_{2}$ emission depends on different parameters such as increased peak flame temperature [17], furnace design [18] and operating conditions [19]. Hence increment in $\mathrm{NO}_{2}$ cannot be attributed to the fuel only.

\subsubsection{Economic Performance}

The energy cost during demonstration was almost twice the baseline cost. The fuel cost per kilogram of product output was NRs 19.74 in the demonstration phase compared to NRs 10.4 in the baseline phase. The main reason for the increased cost was due to high cost of pellets. The pellet cost of NRs 26 per kilogram, significantly higher than the cost of sawdust and woodchips. The average cost of sawdust and woodchips is NRs 10 per kilogram. The pellets were imported from India for demonstration and higher transportation cost resulted into higher cost of pellets. Also, the furnace design required certain quantity of sawdust to be used along with the pellet during the demonstration, which had also resulted into higher fuel cost.

\section{Conclusion}

The scarcity and disrupted supply of the traditional fuel sources coupled with negative environmental impacts have compelled Nepali MSME sectors to look for other locally available alternative energy sources. Though biomass is available in abundant quantity in Nepal, burning biomass in loose form is inefficient and environmentally degrading. With many technologies available for the densification of biomass, pelletizing would be highly preferable as using pellets is much cleaner and efficient. Considerable reduction in energy consumption and environmental emission could be achieved if loose biomass could be replaced with pellets for industrial combustion. But the major hindrance for the promotion of pellets as industrial fuel could be its cost. If the costs could be reduced by initiating large scale production using locally available biomass resources within the country, the scope for the promotion of pellets as industrial fuel can be substantially enhanced. Also, there is need for some modification in furnace design of MSMEs to assist efficient and effective combustion of pellets.

\section{Acknowledgments}

The authors express their sincerest gratitude to Alternative Energy Promotion Center (AEPC) for their valuable guidance and financial support to carry out this applied research. Authors are also grateful to MinErgy Pvt Ltd a consulting firm for conducting this applied research project. Also, gratitude goes to Dantakali Dyeing Industry for showing interest and granting permission to carry out the study in their industry.

\section{References}

[1] D. Ayhan, "Biomass resource facilities and biomass conversion processing for fuels and chemicals," Energy Convers Manag, vol. 42, pp. 1357-1378, 2001.

[2] "U.S. Energy Information Administration," 16 May 2017. [Online]. Available: https://www.eia.gov/energyexplained/index.cfm/data/in dex.cfm?page=biomass_home.

[3] A. Demirbas, "Biomass resource facilities and biomass conversion processing for fuels and chemicals," Elsevier, pp. 1357-1378, 2001.

[4] M. Sharma and S. C. Bhattacharya, "A study of biomass as a source of energy: Nepal," Energy for Sustainable Development, pp. 40-45, 1997.

[5] S. Prajapati, "Study on Alternative Fuels in Brick Kilns," Ministry of Industry, Nepal, Kathmandu, 2017. 
[6] J. Granath, "The Global Wood pellet Market," Ekman, Virginia, 2015.

[7] "Biomass Densification for Energy production," 4 January 2016. [Online]. Available: http://www.omafra.gov.on.ca/english/engineer/facts/11035.htm.

[8] T. Miranda and I. Montero, "A Review of Pellets from Different Sources," Department of Mechanical Engineering, Energy and Materials, Industrial Engineering School, University of Extremadura, Badajoz, January 2015.

[9] "The Comparision Between Biomass Pellets and Coal," 23 February 2017. [Online]. Available: http://www.biomass-energy.org/blog/biomass-pelletsand-coal-comparison.html.

[10] "Zilkha Biomass Energy," [Online]. Available: http://zilkha.com/what-are-pellets.

[11] S. Kafle and R. Prajuli, "Potential biomass supply for agro-pellet production from agricultural crop residue in Nepal," Energy Sources, Part A: Recovery, Utilization, And Environmental Effects, pp. 149-153, January, 2016.

[12] WECS, "Energy Data Sheet," 2014.

[13] P. N. P. Ltd., "Baseline study of selected sector industries to assess the potentials for more efficient use of energy," 2012.

[14] "Annual Report-UNDP in Nepal," UNDP, 2016.

[15] P. D. Kofman, "The production of wood pellets," 2007. [Online]. Available: http://www.coford.ie/media/coford/content/publications/ projectreports/cofordconnects/ccnpellet_production.pdf.

[16] R. Lamichane, "What is stopping the SME Sector," [Online]. Available: http://ventureplus.com.np/what-isstopping-the-sme-sector/.

[17] "Properties of wood fuels used in Finland BIOSOUTH- project," European Comission, 2005.

[18] S. Pandey and R. P. Dhakal, "Pine needle briquettes: A renewable source of energy, International Journal of Energy Science.," International journal of Energy Science, 2013.

[19] H. Wang, "The Effect of Primary Air Distribution on Emissions from Natural Gas Water Heater," Marquette University, 2009.

[20] H. Meissner, "The Effect of Furnace Design and operation on Air pollution from Incinerators".

[21] "Study on Biomass Combustion Emissions," Irish Bioenergy Association, December 2016. 